\title{
Obstructive Sleep Apnea- Dentist's has the major role to play.
}

\author{
Md. Nazmul Hasan, ${ }^{\text {a }}$ Syed M. S. Islam. ${ }^{\text {b }}$
}

Obstructive sleep apnea (OSA) is a serious, lifethreatening disorder ${ }^{1}$ that is characterized as a series of episodes in which a person stops breathing for 10 seconds or longer during sleep. ${ }^{2}$ Sleep disordered breathing is a term which includes simple snoring, upper airway resistance syndrome, and sleep apnea. Patients present with various symptoms, although almost all complain of snoring, witnessed breathing pauses, and excessive day time sleepiness. Simple snoring is a common complaint affecting $45 \%$ of adults occasionally and $25 \%$ of adults habitually and is a sign of upper airway obstruction. ${ }^{3}$ Sleep apnea has also been identified as a possible risk factor for hypertension, dysrhythmias, depression, ischemic heart disease, and stroke ${ }^{.4}$

So how could someone know if she had sleep apnea? Snoring is the major indicator, but not all symptoms are so obvious and audible. A dentist can easily detect the less evident symptoms of sleep apnea and snoring at an early stage. ${ }^{5}$ Obesity is the main predisposing factor for OSA. In nonobese patients, craniofacial anomalies like micrognathia and retrognathia may also predispose to OSA. Other orofacial features that may predispose to OSA, include enlarged palatine tonsils, enlarged uvula, high-arched palate, nasal septal deviation, longer anterior facial height, steeper and shorter anterior cranial base, disproportionately large tongue, a long soft palate, and decreased posterior airway space. ${ }^{6}$ This predisposing factor could easily be evaluated by dentist through a candid conversation with a patients duringtheir primary dental checkup. Moreover their craniofacial characteristics could more easily be evaluated by orthodontist with their routine cephalometric ${ }^{7}$ or $\mathrm{CBCT}^{8}$ evaluation.Adentist may suspect a patient suffers from sleep apnea if the patient complains about lethargy, morning headaches, or dry mouth (specially caused by open mouth breathing during sleep). Dentists are often the first professional to become aware of a potential problem since they are usually in contact with their patients more frequently then physicians. Dentist will then send patients with symptoms of sleep apnea to a sleep medicine specialist who will assess and confirm the patientconditions and severity by polysomonogram (PSG).

Treating a patients with OSA conventionally involve either continuous positive airway pressure (CPAP) by mechanically which often suffer from poor patients compliances due to portability problems, pump noise, dryness of airway, and mask discomfort ${ }^{2}$ or surgical correction craniofacial structure to reshape upper airway. Moreover oral appliances offer an effective alternative to continuous positive airway pressure(CPAP) in the treatment of obstructive sleep apnea (OSA). ${ }^{9}$ Oral devices are basically thermoplastic materials with retainers and supports like mandibular repositioning or advancement device (MRD/MAD), tongue repositioning or retaining devices (TRD), soft palate lifter, tongue trainer. These oral appliances are often designed and custom made by dentist. The American Academy of Sleep Medicine (AAOSM) has recommended oral appliances for use in patients with primary snoring and mild to moderate OSA. ${ }^{3} 1.5 \%$ of patients with OSA have a space-occupying problem that can be directly attributed to their sleep-related upper airway obstruction ${ }^{10}$ requiring surgical correction of upper airway that often done by maxillofacial surgeon or by otolaryngologist. Thus role of dentist in OSA cases involve from initial diagnosis to final management. To emphasize dentist role more prominently American Academy of Dental Sleep medicine (AADSM) recently form and start working conjointly AAOSM, and going to publish their journal on that 
specialty from 2014 titled Journal of Dental Sleep Medicine (JDSM).

[Updat Dent.Coll.J 2013;3(1):01-02]

a. Md. Nazmul Hasan

Assistant Professor, Department of Orthodontics \& Dentofacial Orthopedics, Update Dental College \& Hospital, Dhaka, Bangladesh,

\section{b. Syed M. S. Islam}

Research Assistant Professor, School of Dentistry, Oral Health Center of Western Australia, The University of Western Australia.

\section{References:}

1. Cistulli PA, Sullivan CE. Pathophysiology of sleep apnea. In: Saunders NA, Sullivan CE, eds. Sleep and breathing. New York, NY: Marcel Dekker, 1994; 405-448.

2. Jayan B, Kharbanda OP. Orthodontist's role in upper airway sleep disorders. In: Kharbanda OP. Orthodontics: Diagnosis and Management of Malocclusion and Dentofacial Deformities. $2^{\text {nd }}$ ed. New Delhi: Reed Elsevier India ltd, 2013, pp. 709-725.

3. Practice parameters for the treatment of snoring and obstructive sleep apnea with oral appliances. American Sleep Disorders Association. Sleep 1995;18:511-3.
4. Waller PC, Bhopal RS. Is snoring a cause of vascular disease: An epidemiological review. Lancet 1989;1:143-6.

5. Cistullia PA, Gotsopoulosa $\mathrm{H}$, Marklundb M, Lowe AA. Treatment of snoring and obstructive sleep apnea with mandibular repositioning appliances. Sleep Medicine Review. 2004:8(6);443-457.

6. Padma A, Ramkrishna N, Narayanan V. Management of sleep apnea: A dental perspective. Indian J Dent Res. 2007;8(4):201-209.

7. Flores-Mir C, Korayem M, Heo G, Witmans M, Major MP, Major PW. Craniofacial morphological characteristics in children with obstractive sleep apnea syndrome: a systematic review and metaanalysis. Journal of American Dental Association. 2013;144(3):269-277.

8. Stratemann S, Huang JC, Maki K, Hatcher $\mathrm{D}$, Millere AJ. Three-dimentional analysis of upper airway with cone-beam computed tomography. Am J Orthod Dentofacial Orthop 2011;140:607-15

9. Chan AS, Lee RW, Cistulli PA. Dental appliance treatment for obstructive sleep apnea. Chest 2007;132:693-9.

10. Rojewski TE, Schuller DE, Clark RW, Schmidt HS, Potts RE. Videoendoscopic determination of the mechanism of obstruction in obstructive sleep apnea. Otolaryngol Head Neck Surg 1984;92:12731. 